\title{
A web-based user guide for Sri Lanka Standards 573: Standard Method of Measurement of Building Works
}

\author{
Srinath Perera \\ Gayani Karunasena \& Thilesh Fonseka
}

\begin{abstract}
A brief investigation revealed that the Sri Lanka Standards 573 (SLS573): Standard Method of Measurement of Building Works (SMM), which was first revised in 1999, is generally used in the industry. However, it is also viewed that the SMM is not popular enough because of several issues. This research was aimed at identifying such issues and compiling a "Web-Based User Guide" to make it popular in the industry. The research was focussed on to investigating the problem areas of the SMM SLS 573 and to group them under three headings namely; Measurement rules which do no match to local needs, Areas where clarification is required and Omissions where no measurement rules have been given. The questionnaire survey received a poor response thus a selected number of professionals were interviewed using semi-structured interviews. It was revealed that many people were reluctant to use the SLS573 because of the ambiguities and non-conformity to local practices. With these findings of the research a user friendly and easy to use electronic user guide was developed. This is called as the Web-Based User Guide and it has many advantages over the other methods of popularising the SMM. It is hoped that this new concept will have a changing effect in the industry and the process of standardisation will be a success.
\end{abstract}

\section{Introduction}

The SMM provides a uniform basis for measurement, which allows proper itemisation. The estimator is therefore able to identify costs in a scientific and methodical manner so that pricing becomes less complex. The Bill of Quantities (BQ) will contain the deciding factors for the cost of the project. Any errors in preparation of the $B Q$ will have definite effects on cost. Thus, a proper bill of quantities leads to."accurate tendering'(Wainwright and Whitrod, 1980, p11). In order to serve the needs of the Sri Lankan Building Construction Industry a SMM for Sri Lanka was developed in 1982. However, there exist many ambiguities and discrepancies, which give, rise to arguments in interpreting the measurement rules. A user guide or a practice manual in such instances can solve the problems faced by the users in using the SMM. Therefore the need for a proper user guide has been evident over the years. Although user guides are available for SMM7 (UK), there has not been a single attempt to prepare a user guide for SLS573.

This paper addresses the issue of the need for a User Guide for the Sri Lankan SMM SLS 573 and attempts to set the framework for a comprehensive electronic User Guide published in the World Wide Web through the Construction Industry Information Centre (CIIC) (http://www.ciic.becon.mrt.ac.lk/Standards/ Guide books/User Guides/s573/Index.htm).

\subsection{Aims}

The main aim of this research is to set up the framework for a Web-based User Guide for SMM SLS573 (Sri Lanka Standards Institute; 1999) and to formulate a user-friendly and easy to use web site, which will drive

the local construction industry towards a standardised environment by encouraging good practice as laid down by the local SMM.

\subsection{Objectives}

The following are the objectives of this research project.

i. To encourage good practice in measurement of building woks and preparation of Bills of Quantities in Sri Lanka with the use of SLS573 to achieve standardisation.

ii. To minimise discrepancies and ambiguities in interpretation of rules and definitions of SLS 573.

iii. To use the "Dynamic Web-based User Guide" as a platform to react to the changes in the environment and cater for the needs of the industry.

iv. To provide an interface to the users to actively involve in the development of Sri Lankan Standards by facilitating for queries and comments which will be responded to.

\subsection{Methodology}

The determinant factor of the success of this project is that how far we can find the problem areas of the SLS 573. This proved to be very difficult with the use of a questionnaire due to the poor response. Thus limited semi structured interviews were carried out with a selected number of Quantity Surveyors in ten consultancy organisations. The collected information was then used to develop the Web-Based User Guide. 
Table 1: SMM Usage

\begin{tabular}{|l|c|c|c|c|}
\hline Organisation & $\begin{array}{c}\text { Type of } \\
\text { Organisation }\end{array}$ & $\begin{array}{c}\text { 1982 SLS573 } \\
\text { Used }\end{array}$ & $\begin{array}{c}\text { SLS 5731999 } \\
\text { (revised)Used }\end{array}$ & $\begin{array}{c}\text { No SMM } \\
\text { Used }\end{array}$ \\
\hline Organisation 1 & Private & No & In general & Yes \\
\hline Organisation 2 & Private & No & No & No \\
\hline Organisation 3 & Private & No & In general & Yes \\
\hline Organisation 4 & Government & No & In specific items & Yes \\
\hline Organisation 5 & Private & No & No & No \\
\hline Organisation 6 & Government & No & In general & Yes \\
\hline Organisation 7 & Semi Govt. & No & In general & Yes \\
\hline Organisation 8 & Private & No & In general & Yes \\
\hline Organisation 9 & Private & No & In general & Yes \\
\hline Organisation 10 & Private & No & In general & Yes \\
\hline
\end{tabular}

Also this was backed by a literature survey to collect published information regarding the existing problems of SLS 573.

\section{The Problem Context}

\subsection{Investigation into the Sri Lankan practice of BQ preparation}

The current practice in the building construction industry is to measure quantities generally in accordance with the principles laid down by the local SMM. Therefore as far as a quantity surveyor's task is concerned he/ she can prepare a BQ with little or no regard to the rules of the SMM. This is because he/she can still be preparing according to the general principals laid down by the SMM. Therefore it is essential to note this fact and encourage the essentials of good practice.

Although, there is a need for a separate section for preliminary items (where Contract Sum exceeds Rs.5 Million) some BQs lack proper itemisation of such work. The Treasury Circular 286 - FIN 1076/203, has stipulated the need for a separate section for preliminary items and this has been included by the SLS573 by having a separate section for preliminaries. However, often this is ignored and left for the contractor to price in his unit rates. Institute for Construction Training and Development (ICTAD) has a specimen preliminaries bill, which is a guideline to be used by the consultants. Yet these problems exist in the industry without any hope for possible development in the near future.

\subsection{The extent of usage of the SLS 573: SMM}

In an interview of twenty Quantity Surveyors in ten organisations it was revealed that the SLS573: SMM was only used as a general adaptation. The word generally refers to that they adopt the SMM in measuring a limited number of items and often avoid measurement of all items that can be measured as stated in the SMM. Many items are often grouped together and used as in the case of a composite item. This is a deviation from the SMM. The following table is a summery of outcomes from the interviews. It was found that only one large Government Organizations attempted to use the SLS573 in specific items.

\subsection{Understanding the Problem}

In determining the causes of deviation from the SMM, the following two problems need to be considered.

i. Why Consultants are reluctant to prepare BQs according to a specific SMM.

ii. Why Contractors are reluctant to price detailed BQs prepared according to SMM.

These two problems are intertwined which makes it difficult to implement proper practice in accordance with Standard Method of Measurement. The attitudes of the consultants and the contractors as identified in the interviews help to understand the answers to the above questions. It is noted here that the contractor's attitude was based on the consultant's opinion who participated in the interview.

\subsection{Consultant's Perspective}

The following are a summary of the views shared by many consultants.

i. Drawings are not prepared in detail at the time of preparation of $\mathrm{BQs}$. Thus detailed itemisation is not possible.

ii. Standards lack clarity to a larger extent and the Quantity Surveyor is left with no assistance to solve such matters.

iii. Consultants have observed that contractors do not consider the relationships between items of work. Same costs are included in different items resulting in higher tender prices. This is because contractors are more familiar with all inclusive prices, and even when items have been separately identified they tend to price as usual ignoring the detailed itemisation.

iv. Consultants some times lack experienced Quantity Surveyors competent enough to follow 
the SMM. Often the case is that there are lot of people who have emerged to the Q.S profession with their experience in the industry and not with adequate theoretical background. It is difficult for them to switch from their traditional ad-hoc practices to new standards that have been developed.

v. The time available to prepare a BQ is sometimes very short that detailed items cannot be measured.

\subsection{A hypothesis of the Contractors' Perspective}

Many consultants are of the opinion that the following factors have influenced the contractors to depart from the SMM practice.

i. Lack of resources in estimating staff, time constraints within which tenders should be submitted etc.

ii. The cost information available for the contractors is not updated frequently and may not be suitable for accurate estimating.

iii. The contractors have not classified their overhead expenses and project costs to a sufficiently accurate and organised method.

\subsection{Major problem areas of the SLS573: SMM First Version}

While trying to investigate the causes of deviation from the SMM SLS 573, the following types of problems were identified.

i. Rules that do not cater for the needs of the local industry.

ii. Lack of clarity.

iii. Omissions where no rules have been stated. The above identified problems are analysed in detail below.

1. Bules that do not cater for the needs of the local industry

a) Some of the rules in SMM SLS573: have created loopholes in which contractors can play out the client in many ways. One such situation is where general rules of the SMM requires, quantities exceeding 10 units to be given to the nearest full unit. The contractor therefore can earn what is called as "Decimal Money". ie where decimals multiplied by huge rates for example for concrete items can result a large sum of money (Measurement rule 4.4).

b) The SMM refers to two different terms as "Prime Cost Sums" and "Provisional Sums". "Prime Cost Sum" is defined as a sum provided for work or services to be executed by a nominated subcontractor. The term "Provisional Sum" is defined as a sum provided for unforeseen works or for the value of works where the quantity of work required cannot be accurately determined at the time of $B Q$ preparation. However, the ICTAD Conditions of
Contract does not identify a difference between the two terms and uses the common term" Provisional Sums" to cover both situations. This is an example of lack of consistency in the two documents (Section B.16, B.17).

C) According to Samaraweera, (2000) the only reason behind grouping together work items regardless of its position according to the level of the floor is to minimise the number of items in a BQ. However, it is evident that at pre-contract stage in estimating (eg: the price of brickwork) the estimator is required to compute an average rate applicable to all floor levels and to arrive at an average rate the estimator is required to compute the cost of brick work in each floor. Further, during the post contract stage, a variation involved in brickwork will have to be valued on a separate rate rather than using the average rate quoted in the priced BQ. (Definitions rule D1.d)

\section{Lack of clarity}

a) Measurement of electrical installation is difficult. A non-specialised measurer will not be familiar with the terminology of this section. The user guide may include information to be of help for a novice measurer to acquire the required skills in measurement of electrical works. (Section S)

b) The measurement rule for the measurement of Rubble steps is not clear (Section G2.19).

\section{Omissions where no rules have been stated}

a) The construction industry of Sri Lankan is evolving and new techniques, methods of construction and new materials come into the market frequently. Therefore, the SMM should be updated to provide measurement rules for such items. For example new sections should be included for the measurement of PVC doors, Windows, Fibre-Glass doors \& windows and partitions.

b) There is no rule provided for the measurement of face-work. However, the definition D4 includes a definition for face work. (Section G1.1).

\section{The Solution Strategy}

3.1 Possible steps to be taken to improve the use of $\underline{\text { SLS573 }}$

The first solution which should be found is, a way to implement the SMM into practice. The following proposals may have a positive influence in implementing the use of the SMM SLS 573.

i. To introduce new clauses into the conditions of contract that will make it reasonably appropriate to use the SMM. Molloy, (2001) states that where there are mandatory rules requiring a SMM to be used, disputes concerning measurement matters are quite rare.

There cannot be very rigid clauses however in the Conditions of Contract to force the Quantity Surveyor to prepare the $B Q$ according to a 
specific SMM. This is because the SMM cannot foresee every situation in construction and therefore may not be containing measurement rules for certain situations. But it would be appropriate to amend clauses and insist on the use of the SMM and leave flexibility to depart from it only where it is reasonably acceptable and the new or modified measurement rule or procedure is stated or defined in the Preambles of $B Q$. Even though it may not confirm to the relevant named SMM in the contract, it will always be considered as an acceptable departure from the SMM.

ii. Minor changes to the government's tender procedure can make a positive influence. This can be achieved by introducing a procedure to review the $B Q$ to ascertain that the document has been prepared substantially according to the local SMM by the Technical Evaluation Committee (TEC) appointed by the Tender board for the project.

iii. Another step is to request all banks to adopt a policy to accept BQs prepared according to the local SMM in granting loan facilities.

iv. Training programmes are needed in the industry to encourage the use of SMM and insist on the fact that preparation of a Bill of Quantities itself is a professional exercise (Jayalath, 2000).

Institute of Quantity Surveyors Sri Lanka (IQSSL) can take a leading role in conducting seminars and gathering professionals together to introduce standards in a more influential manner. Awareness programmes can be conducted through the Organisation of Professionals Association (OPA). Contractors can be educated with regard to the benefits they would gain in complying with standards and request their co-operation in pricing tender documents in a more scientific method. ICTAD can organise Seminars, Workshops etc to that effect. Also a conceptual change within designers and architects should take place to prepare drawings with details and better standards.

\subsection{The need for a User Guide}

Many ambiguities in the SMM occur due to lack of clarity in the measurement rules given in the tabulated form. Due to the format of such a document it is difficult to clearly explain each and every clause and its applicability. If it aught to do so it would remove the advantages of having a tabulated form with ease of reference. Therefore to deal with the problem of ambiguities it is necessary to produce a separate document in the form of a user guide.

\subsection{Advantages of a user quide}

The following are the advantages of having a user guide.

i. By removing ambiguities in interpretations of different rules it contributes positively to the intended uniformity of the SMM. ii. It provides a better understanding of the SMM.

iii. It encourages users to properly adhere to the SMM since its rules are clearer and unambiguous.

iv. When lesser problems are found the SMM becomes more popular.

v. It will result in the production of Bills of Quantities with high standards.

vi. It will also reduce the number of disputes and incidence of arbitration caused by ambiguities related in Bill of Quantities.

\section{User Guides available for SMM documents}

A few of user guides or supporting documents published for various SMM's found in industry are given below.

i. Practice Manual SMM6 (Royal Institute of Chartered Surveyors and The National Federation of Building Trades Employers, 1983).

ii. A Code of Procedure for SMM7 (Royal Institute of Chartered Surveyors and Building Employers Confederation, 1988).

iii. CESMM3 Handbook $3^{\text {rd }}$ Edition (The Institute of Civil Engineers and The Federation of Civil Engineering Contractors, 1991).

iv. Civil Engineering Quantities $5^{\text {th }}$ Edition (The Institute of Civil Engineers and The Federation of Civil Engineering Contractors, 1991).

v. Standard Method of Measurement (SMM) of Building Works: Electronic Guide (Property and Construction Electronic Commerce group.)

Most user guides are found in the text form with its inherent disadvantage of not being able to modify and amend frequently. The following are the basic features found in different user guides.

i. The document is categorised in the order of the work sections of the SMM.

ii. Only specific problem areas are discussed with diagrammatic explanations.

iii. Some user guides include example BQs to demonstrate the application of different rules using special drawings.

\section{The Web-Based User Guide (WBUG)}

The importance of having a user guide for the SMM is to resolve ambiguous situations. However, there is no such user guide published for the SLS 573. The WebBased User Guide is intended to remove this vacuum and place a step in to the future. This is a novel concept and its advantages over the conventional methods of popularising the use of SMM make it a better solution for many problems. 


\subsection{A model of user requirements}

The salient features of available text based user guides have been used as a point of reference in developing the following user requirements model.

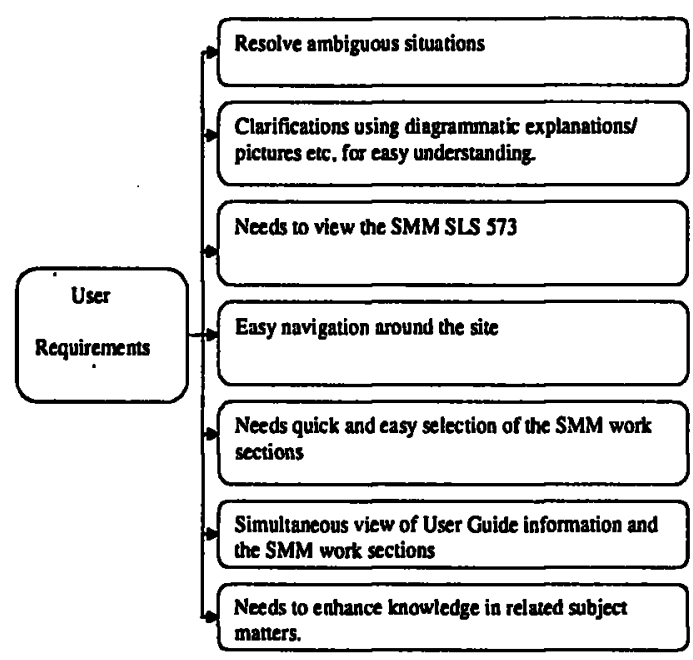

Figure 1: Requirements Model

\subsection{Information to be provided}

The most important feature of the Web Based User Guide (WBUG) is to eliminate ambiguity with regard to the rules of the SMM. It was first necessary to identify the areas of ambiguity, which the current Quantity Surveying practitioners have come across. The WBUG attempts to provide explanation to these identified problems and remove all ambiguous situations.

\subsection{Development of WBUG \& validation process}

The WBUG has been integrated using many different web pages. One set of web pages contains the SLS573 document. Another set contains user guide information. These two sets have been integrated into a framed web page. The following figure 2 illustrates an overview of the system.

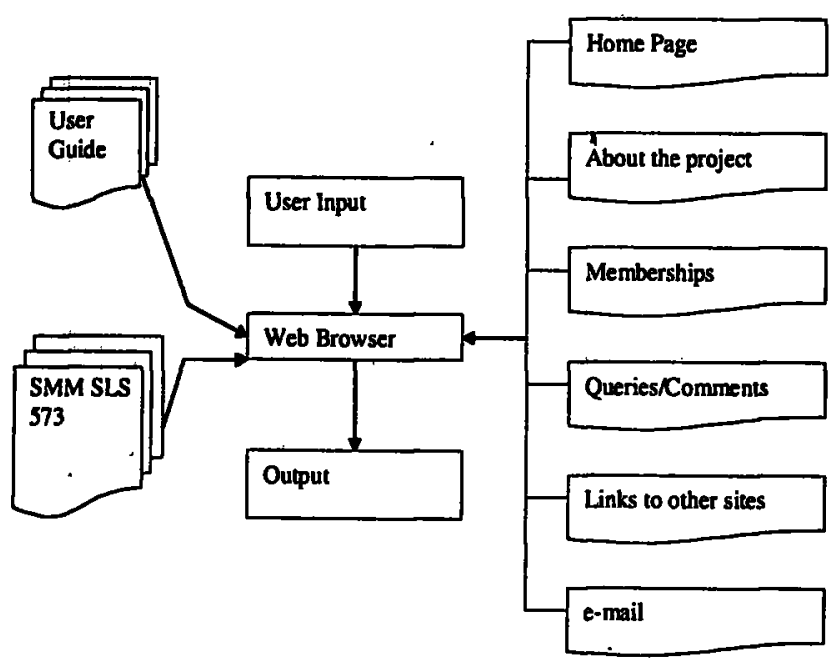

Figure 2: An overview of the WBUG system
The tool used for the development of web site was Microsoft FrontPage due to its user friendly interface and visual programming environment which generate the underlying codes of Hyper-Text Mark-up Language (HTML). The wide range of facilities and functions available and the ease of leaming make it an ideal choice for the web development. Web testing concentrates on checking whether the system does what is intended. For this purpose fault-based testing was employed. Program was tested by entering actual data and checking whether the requirements are achieved.

\subsection{Understanding the WBUG system}

\section{i. The System Interface}

Figure 3 below shows the interface of the WBUG system.

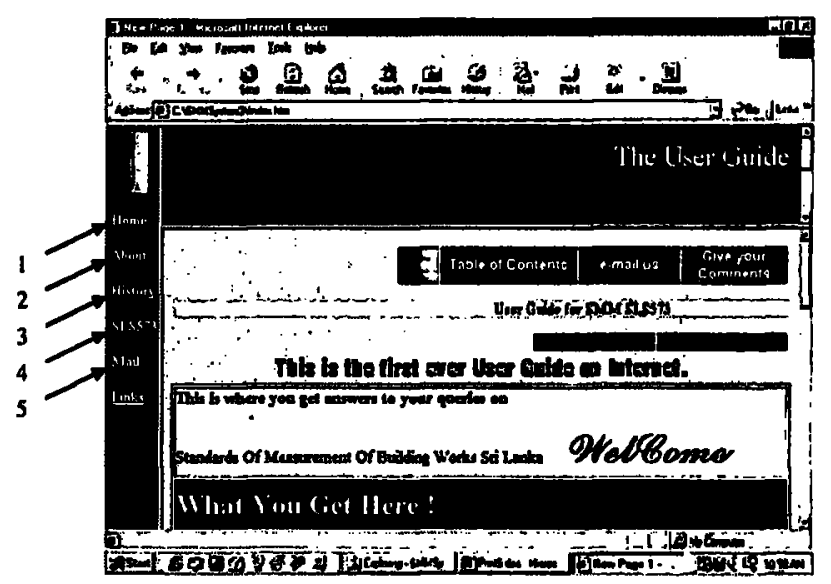

Figure 3: User guide interface 1

Table 2 gives the detail illustration for the system Interface.

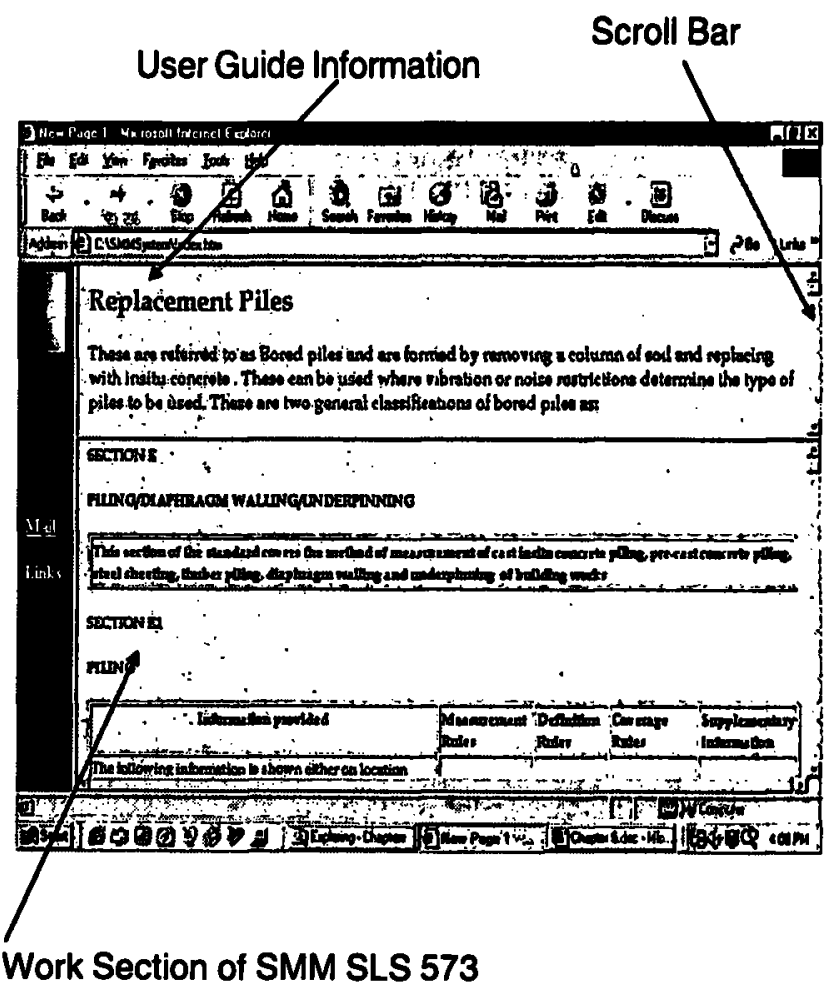

Figure 4: User guide interface 2 
Table 2: Components of system Interface

\begin{tabular}{|c|l|}
\hline Components & \multicolumn{1}{|c|}{ Description } \\
\hline 1 & $\begin{array}{l}\text { The button "About" is linked with a page that contains information about the project. It } \\
\text { will give details of the people involved in developing it and what type of project it is, the } \\
\text { aim \& objectives. }\end{array}$ \\
\hline 2 & $\begin{array}{l}\text { The button "History" is linked with a page that contains the background information to } \\
\text { this project. }\end{array}$ \\
\hline 3 & $\begin{array}{l}\text { This page contains hyperlinks to the work sections of the SLS 573. By selecting this } \\
\text { page the user is able to find a particular work section. Within that work section he is } \\
\text { able to browse to a particular point of interest and find the user guide information. If } \\
\text { such information is not available in that particular place the user can submit it as a } \\
\text { query to the WBUG development team (Figure 3). }\end{array}$ \\
\hline 4 & $\begin{array}{l}\text { This is a form where user can input his/her information and become a member to the } \\
\text { system. It is intended to restrict downloading facilities from the non-members of the } \\
\text { system. This will become important when this project is implemented as a commercial } \\
\text { project in future. }\end{array}$ \\
\hline 5 & $\begin{array}{l}\text { The user is given freedom to select various other sites related to construction industry and } \\
\text { browse through them while being in this system. The other sites will appear in separate } \\
\text { windows. }\end{array}$ \\
\hline
\end{tabular}

\subsection{Specific Advantages of a Web-Based User Guide}

Apart from all other advantages resulting from a user guide, following facilities are unique to the Web-Based User Guide.

i. It combines modern information technology and construction industry resulting in a popularisation of SLS 573. Local construction industry will be driven to a standardised environment as a result.

ii. Users are able to browse through the user guide along with the SMM and more knowledge and broad understanding can be taken.

iii. User guide and the SMM are available in soft copy format.

iv. Web pages can be frequently updated. Therefore user can obtain timely information and also they can obtain all other benefits provided by the web site.

v. Users are able to forward their queries and comments regarding the SMM where fast development of the SMM can be expected. Also frequent updates can be made to answer such queries and this information can be effectively communicated.

vi. Wide variety of professionals can be addressed through the process.

vii. The site can be accessed regardless of time, location and other barriers, which in other circumstances would have existed. viii. Computers and Internet facilities will become less expensive and readily available in future. Thus it would be easy to use the system than referring to latest hard copies.

\section{$\underline{5.6 \text { Limitations }}$}

The following are some of the limitations identified.

i. This project requires good user participation. Although most people are keen on having a user guide for the SLS 573 it does not guarantee participation. The biggest barrier would be the lack of Internet access to all users.

ii. Authorities should facilitate the implementation of this project as a problem solver in the industry. The ICTAD or its successor should support the implementation.

iii. The SLSI as the governing body that has the authority of the publication of SLS 573 needs to recognise this type of development to gain the advantages of a Web-Based User Guide.

\subsection{The Current Status and Possible Future Development}

This section briefly identifies the status of the WBUG system development and it further development plan.

i. The user guide is prepared for selected work sections and the SMM is available only for 15 
sections. This can be implemented to cover all the work sections of the SMM and develop the respective user guide modules. However, user participation in bringing forward the problems is a critical factor in this development.

ii. Other areas that will encourage users to visit the site need to be developed. These are briefly identified below.

a. News channel displaying job opportunities, current trends in the industry and other relevant professional information.

b. Facilities to conduct forums and online discussions with professionals around the world where they can communicate and share views on topics related to the construction industry.

\subsection{Directions for Further Research}

The SMM stipulates standards for measurement. It allows freedom to the surveyor to decide the format of presentation of the $\mathrm{BQ}$. This causes many different formats being produced at different organizations. It is therefore necessary to develop a Code of Practice for the preparation of BQs. This Code of Practice should be intended to serve the following purposes.

i. To provide guidelines for the preparation of $B Q$.

ii. To provide guidelines on how to bill.

iii. To determine a standard format of the $B Q$.

iv. To identify the post contract usage of the BQ.

V. To introduce computer aided BQ preparation and identify its advantages.

Both a User Guide and a Code of Practice together will have a strong influence in striving to standardise and provide high quality $B Q$ preparation.

\subsection{System Requirements and Guideline for Execution}

The system is developed in windows environment and it needs windows 98 or above operating system and Internet Explorer 5.0 or above as the browser for its execution. The present version of the web-based user guide can be viewed at http://wuw.ciic,becon.mit.ac.lk/ Standards/Guide books/User Guides/s573/Index.htm.

\section{Conclusions}

The need for a Standard Method for Measurement (SMM) for building works has been identified for a considerable period. As a result many different SMMs have been developed around the world. The SMM provides a uniform basis for measurement, which allows proper itemization of work to be carried out. The estimator is therefore able to identify costs in a scientific and methodical manner so that pricing becomes less complex. SLS 573 of 1982 was the first SMM developed for the Sri Lankan construction industry. This was subsequently revised in 1999. But it is viewed that the SMM (Revised 1999) is not highly popular because of several issues within it. This research was aimed at identifying such issues and compiling a "Web-Based User Guide" (WBUG) as a solution to these problems and thereby standardize the information. The objective of WBUG was to provide a platform to react to the changes in the environment and cater to the needs of the construction industry.

A questionnaire was used to obtain information and same was used to conduct semi-structured interviews with professionals from ten consultancy organization. This revealed that many people are reluctant to use the SLS573 because of the ambiguities and non-conformity to local practices.

The identified problems have been grouped under three headings. They are, measurement rules, which do no match the local needs, areas where further clarification is required, and omissions where no measurement rules have been given.

As a solution to these problems, a web-based user guide was developed. With the use of this new concept it is envisaged that there will be a considerable improvement to the industry practice and thus process of standardization will be a success. Following are some of the facilitates unique to a Web-Based User Guide: it will combine modern information technology with the needs of local construction industry resulting in a standardized environment for SLS573. It will also enable users to browse through the user guide along with the SMM achieving greater levels of knowledge and broad understanding. The user guide and the SMM are available in soft copy format while providing timely information. The user guide will be an evolving webbased document developing with its usage. It also encompasses all other benefits and facilities provided by the web site such as, users being able to forward their queries and comments regarding the SMM, communication of frequent updates and wider reach. The web site can be accessed regardless of time, location and other barriers, which in other circumstances would have existed. It is expected that similar web. based user guides which are dynamic and evolving will emerge in future providing the construction industry state of the art solutions for its continuing problems.

\section{References}

Jayalath,R.A.C. (2000). SLS 573 SMM Revision 1999 for Building Works- Contractors' perspective, Seminar Proceedings: Introduction to the Standard Method of Measurement of Building Works SLS 573 Revised 1999

Molloy,J.B.(2001), Civil Engineering Measurement Disputes URL: http://www.hkis.org.hk/publication/ surveying/v9i8/feature.html, 01/09/2001,11.30AM.

Royal Institute of Chartered Surveyors and Bullding Employers Confederation, (1998). Standard 
Method of Measurement of Building Works, $7^{\text {th }}$ ed.(Revised), Eyre \& Spottiswood, Kent UK

Royal Institute of Chartered Surveyors and Building Employers Confederation, (1988). SMM7 a Code of Procedure for Measurement of Building Works, RICS \& BEC, London.

Royal Institute of Chartered Surveyors and The National Federation of Building Trades Employers, (1983). Practice Manual SMM6 Amended November 1983, RICS, London.

Samaraweera,D.(2000). Comparison of SMM SLS573 1982 edition with SMM SLS 573 revised 1999, Seminar Proceedings: Introduction to the Standard Method of Measurement of Building Works SLS 573 Revised 1999.

Sri Lanka Standards Institute, (1999). Sri Lanka StandardMethod of Measurement of Building Works (first revision), Sri Lanka Standards Institute, Colombo.

The Institute of Civil Engineers and The Federation of Civil Engineering Contractors, (1991). CESMM3 Civil Engineering Standard Method of Measurement, $3^{\text {rd }}$ ed., Thomas Telford Services Ltd, London.

Wainwright, W.H. \& Whitrod, R.J. (1980), Measurement of Building Works, $2^{\text {nd }}$ ed.,Anchor Brendon Ltd., Tiptree, Essex

\section{Bibliographic References.}

Atkinson,D. (December,2000), Bills of Quantities-URL: http://www.atkinson-law.com/main/Atkinson-law/ Cases\&Articles/Articles/Bills of Quantities.htm, 15/ 08/2001 10.15 AM.

Chandrasena,H.D.(1999), Standard Method of Measurement of Building Works, Seminar
Proceedings: Introduction to the Standard Method of Measurement of Building Works SLS 573 Revised 1999.

Dissanayeka, S.(2000), Computer Aided Bill Preparation, Department of Building Economics University of Moratuwa, Moratuwa.

Miskin, T. (1993), Sri Lanka - a history of growth Journal of The Building Economist, June/July p14.

Myles, R.T. (2001), Bills of What ?- The Origin of Bills of Quantities, Seminar Proceedings: Controlling Construction Costs Effectively, September $5^{\text {th }} 2001$, URL:http://www.hanscombglobal.com/ hmriuly 1991.htm 01/09/2001 11.30 AM.

Royal Institute of Chartered Surveyors and Building Employers Confederation, (1988), Standard Method of Measurement of Building Works, $7^{\text {th }}$ ed., Eyre \& Spottiswood, Kent UK.

Sierra, J., (1984a), Bills of Quantities - The Roots of the Quantity Surveyor Journal of The Building Economist , March, p379.

Sierra, J., (1984b), Bills of Quantities - The Roots of the Quantity Surveyor Journal of The Building Economist , June, p10.

Stern, J., (1999), World Wide Web Marketing, $2^{\text {nd }}$ ed., John Wiley \& Sons inc., New York.

Weisskopf, G., (1999), Microsoft FrontPage 2000 in 21 Days, Macmillan Computer Publishing Ltd.,New York.

Willis, C.J. and Newman,D., (1988), Elements of Quantity Surveying, $8^{\text {th }}$ ed.,Crosby Lockwood \&Sons Ltd., London.

Yeo,K. and Marsden, P., (1993), Australian Standard Method of Measurement of Building Works - An Evaluation of the Fifth Edition, The Journal of The Building Economist, December, p11

Zakour,J., Foust,J. and Kerven,D., (1997), HTML 4 How-To, Waite Group Inc., California. 